\title{
Operating DC Circuit Breakers with MMC
}

DOI:

10.1109/TPWRD.2017.2658540

\section{Document Version}

Accepted author manuscript

Link to publication record in Manchester Research Explorer

\section{Citation for published version (APA):}

Cwikowski, O., Wood, A., Miller, A., Barnes, M., \& Shuttleworth, R. (2017). Operating DC Circuit Breakers with MMC. IEEE Transactions on Power Delivery, PP(99). https://doi.org/10.1109/TPWRD.2017.2658540

\section{Published in:}

IEEE Transactions on Power Delivery

\section{Citing this paper}

Please note that where the full-text provided on Manchester Research Explorer is the Author Accepted Manuscript or Proof version this may differ from the final Published version. If citing, it is advised that you check and use the publisher's definitive version.

\section{General rights}

Copyright and moral rights for the publications made accessible in the Research Explorer are retained by the authors and/or other copyright owners and it is a condition of accessing publications that users recognise and abide by the legal requirements associated with these rights.

\section{Takedown policy}

If you believe that this document breaches copyright please refer to the University of Manchester's Takedown Procedures [http://man.ac.uk/04Y6Bo] or contact uml.scholarlycommunications@manchester.ac.uk providing relevant details, so we can investigate your claim.

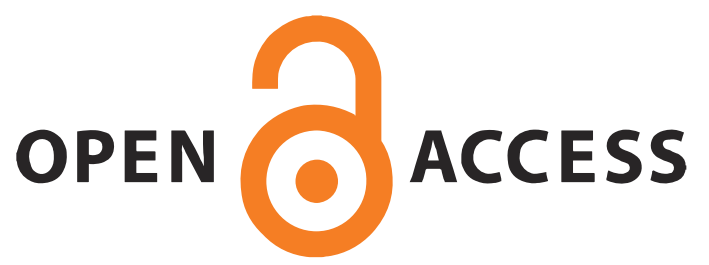




\title{
Operating DC Circuit Breakers with MMC
}

\author{
Oliver Cwikowski, Alan Wood, Member, IEEE, Allan Miller, Senior Member, IEEE, Mike Barnes, \\ Senior Member, Roger Shuttleworth
}

\begin{abstract}
High Voltage Direct Current (HVDC) grids may be protected from dc faults through the application of HVDC circuit breakers. Recent advances in dc circuit breaker technologies may allow faults in the de grid to be cleared without a permanent loss of power to the connected ac grids. The requirements for the protection have yet to be fully defined; especially where half bridge modular multi-level converter controls are concerned. This paper investigates integrating dc circuit breakers with half bridge MMC converters, specifically looking to at how to recover from a pole-to-pole fault. The fault response of the converter to a fault is analyzed in depth. This analysis highlights key stages in the converter response to a dc fault, allowing the MMC fault currents to be predicted. This analysis is then verified in PSCAD simulations and the power flow recovery is shown. The converter controls are investigated, improvements made to the power flow recovery, and the need for arm current controllers highlighted.
\end{abstract}

Index Terms - HVDC, Grid, Protection, dc, Circuit breaker VSC, MMC, Control.

\section{INTRODUCTION}

$\mathrm{H}$ IGH Voltage Direct Current (HVDC) circuit breakers are being considered as a potential method of providing short circuit protection in future HVDC grids [1]. Presently, only two voltage source converter (VSC) HVDC grids exist in the world $[2,3]$. The power rating of these grids is low enough, relative to the maximum infeed loss limitations, to allow dc faults to be cleared through a philosophy of current diversion and ac side isolation, which is the traditional choice for VSC HVDC transmission.

In future grids, if the infeed loss requirements of the ac grids cannot be met with the traditional protection, new technologies will be needed. Two new technologies being considered are: Fault Blocking Converters (FBCs) and HVDC circuit breakers.

Recent advances in HVDC circuit breakers show short interruption times $(<5 \mathrm{~ms})$ can be achieved with novel topologies [4-6]. Many topologies have been proposed and

This paper was submitted for review on the 29/06/2016. This work was supported in part by the Engineering and Physical Sciences Research Council and National Grid under projects EP/L021552/1 and TAO/22360. Special thanks to Dr Paul Coventry, Dr Antony Beddard, and Prof Jan Evans-freeman for their support in this project.

O. Cwikowski, M. Barnes, R. Shuttleworth are with the University of Manchester, Manchester, M139PL UK (e-mail: oliver.cwikowski@postgrad.manchester.ac.uk, mike.barnes@manchester.ac.uk, roger.shuttleworth@manchester.ac.uk).

A. Wood and A. Miller are with the University of Canterbury, Christchurch, 8041, New Zealand, (e-mail: alan.wood@canterbury.ac.nz, allan.miller@epecentre.ac.nz). industrial prototypes have been developed.

Several FBC architectures have been proposed, along with associated novel control schemes [7-10]. These converters may be used in conjunction with HVDC circuit breakers to reduce equipment requirements and minimize the disturbance that is caused to the ac grid by a dc fault $[11,12]$.

However, HVDC breaker interactions with the control of Half Bridge (HB) Modular Multi-level Converters (MMCs), the presently preferred topology, have received little attention. The impact fault clearing will have on the HB-MMC's operation and the disturbance seen by the ac grid, are important areas of study in order to assess the suitability of future HVDC connections and protection requirements.

The impact that dc protection systems have on the operation of the ac and dc grids has been investigated previously [13]. However, such analysis looks at the impact of the HVDC circuit breakers on voltage stability, and not when faults occur. System integration aspects are discussed in [14], but they do not look at the converter fault response or recovery in depth.

Fault currents have been investigated in [15], but assume that the dc fault current is significantly larger than the ac side fault currents and that the converter takes no preventative action against dc faults.

Controls have been investigated for the HB MMC when the converter is not blocked during a dc fault, implying a high dc side impedance [16]. Such control is excellent for the converters in the grid which are not exposed to a significant over current.

This paper investigates how the HB MMC responds and recovers from a pole-to-pole fault. PSCAD simulation results are used to verify the fault analysis and it is shown that additional converter controls can be used to prevent unnecessary blocking of the converter, improving the power flow recovery with respect to the ac grid.

The paper's main contribution is detailed analysis of a terminal pole-to-pole fault. The fault analysis can be used to predict fault currents and if modified can be used to solve for the converter's arm currents. This work will also allow the initial conditions relevant to controller design to be predicted, which will be useful for the designs of more suitable controllers. This paper discusses some of the challenges in developing a robust controller and in predicting the state the converter will be in during the recovery process.

\section{OPEN GRID PROTECTION}

Open Grid dc protection was first proposed by GE/Alstom in [17], and is an alternate way to operate dc circuit breakers, 
and was chosen for this work as it allowed the protection sequence of Fault-Isolation-Reclose-Recovery (which is the basic duty for a circuit breaker) to be investigated for a single converter easily. This protection philosophy was developed to reduce the number of dc circuit breakers, component ratings, and reduce operating time of the dc protection system.

When operating the circuit breakers with an Open Grid philosophy, when any circuit breaker detects a fault on the system, it first opens, even before it has been confirmed that the fault is within its protective zone. As all circuit breakers in the dc system have been opened, the fault is definitely cleared.

A method of establishing which circuit breakers to reclose is required, and will be performed by $d c$ relays; for this paper it is assumed that the breakers always reclose for the converter under investigation, however significant developments are being made in the area of dc relays [18].

This circuit breaker operation allows the protection sequence for a single converter to be analyzed irrespective of grid topology or circuit breaker relaying method.

The system under investigation in this paper is shown in Fig. 1. First, a pole-to-pole fault is applied to the MMC converter. The fault is cleared by a HVDC circuit breaker, reducing the over currents. The converter is then able to unblock and attempt to reestablish power flow to the ac grid. This paper describes and improves this process. The pole-topole analysis is general enough to be applied to any $\mathrm{HB}$ MMC, however for different protection system designs the timing of key transitions will change.

\section{HVDC CIRCUIT BREAKERS}

HVDC circuit breakers are required to generate their own zero crossings. This has led to a number of topologies being developed that contain large power electronic elements. Out of these designs has come a standard type known as Hybrid breakers. Hybrid breakers attempt to combine the benefits of mechanical circuit breakers and power electronic switches, to form high speed, low loss dc circuit breakers. Several manufacturers have developed industrial prototypes that are of the hybrid form [5, 19]. Plans exist for a full scale HVDC circuit breaker to be installed [6].

For the purposes of this paper the circuit breaker has been modeled as an ideal mechanical switch with an interruption delay, in parallel with a semiconductor circuit breaker, as shown in Fig. 2[14]. The semiconductors are protected from overvoltage by a varistor stack. The parameters used in the circuit breaker model are given in Table I.

The semiconductor stack is modeled as a single device (per direction) with parameters scaled to match the stack of devices, using data from [20].

The knee voltage refers to voltage across the varistor at which it starts to conduct a significant current $(10 \mathrm{~A}) ; K_{v}$ is the ratio of peak voltage across the varistor to the knee voltage.

An RCD snubber circuit is also simulated across the secondary branch, and is required to limit the turn off losses in the main breaker; this has been modeled as a single RCD snubber circuit with equivalent stack parameters.

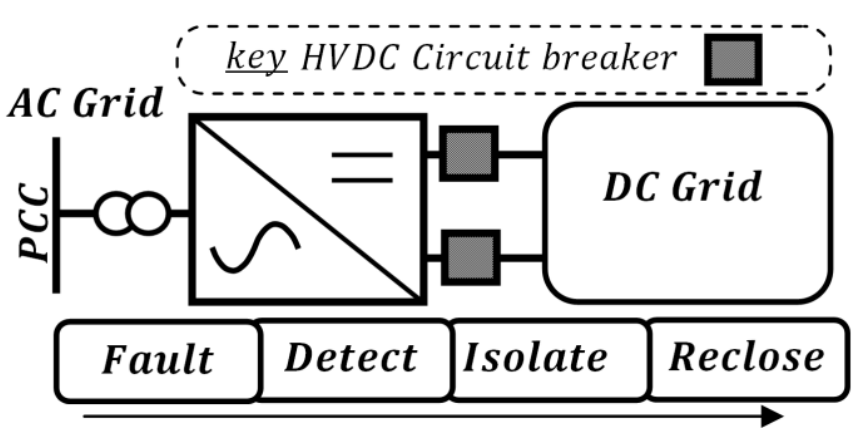

Fig. 1. System under investigation.

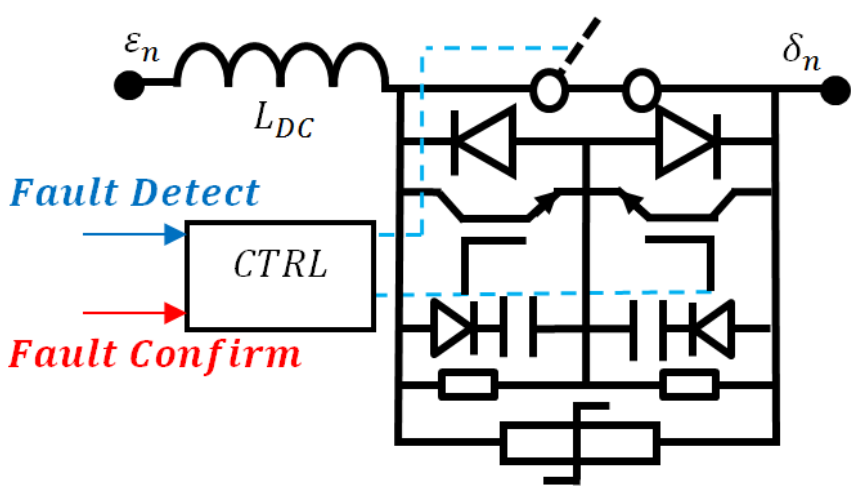

Fig. 2. Layout of circuit breaker model.

TABLE I

Circuit Breaker Parameters.

\begin{tabular}{cccc}
\hline \hline$L_{d c}$ & $0.1 \mathrm{H}$ & Snubber Cap & $0.234 \mu \mathrm{F}$ \\
\hline$V_{\text {on }}$ & $904 \mathrm{~V}$ & Interruption Time & $4 \mathrm{~ms}$ \\
\hline$R_{\text {on }}$ & $0.1 \Omega$ & Detection Time & $1 \mathrm{~ms}$ \\
\hline $\begin{array}{c}\text { Number of } \\
\text { series devices }\end{array}$ & 149 & Knee Voltage & $320 \mathrm{kV}$ \\
\cline { 3 - 4 } & & $K_{v}$ & 1.5 \\
\hline \hline
\end{tabular}

\section{System GRounding AND CABLE Model}

\section{A. Grounding}

The system grounding for the symmetric monopole system used is shown in Fig. 3. The cable's sheath is grounded at each converter station and the ideal three phase star voltage source has a grounded star point in each AC grid [21].

The grounding of the converters is an important consideration for MMCs and changing the grounding configuration will inherently change the fault currents, as there is a different electrical circuit. There are several options for grounding in meshed HVDC grids [22]. However, the analysis presented in this paper can be modified to suit changes. There will be different methods of calculating fault currents for typical de grid layouts and ground schemes.

\section{B. Cable Model}

The cable is represented using a Frequency Dependent Phase Model (FDPM) and is parameterized for a $300 \mathrm{kV}$ XLPE cable [23]. In this paper the cable voltage is commonly referred to, and its location is shown in Fig. 3 as $V_{C a b}$. This voltage will oscillate during a dc fault depending on the cable, 


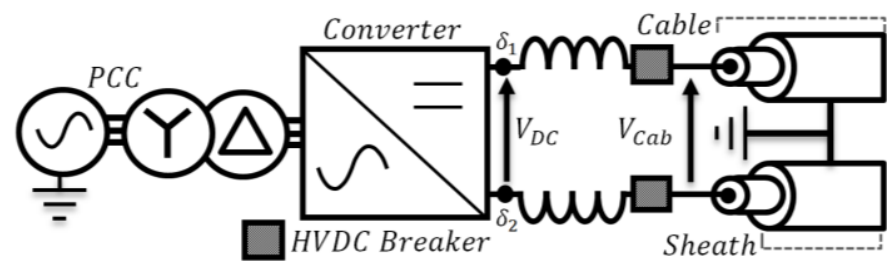

Fig. 3. System grounding and cable voltage.

cable joints, fault location, and impedance of the fault. Changes in grid structure would also influence this voltage, such as lines being out of service or additions to the DC network. No attempt is made to make exact predictions of the cable's influence over the fault currents in this paper as detailed knowledge of what transients would exist on the line would be required to understand its full impact. All such discussion surrounding the potential impact this could have on the system is therefore qualitative.

\section{HB-MMC Pole-to-Pole Fault Analysis}

The layout of an MMC is shown in Fig. 4. The MMC is made from six arms which consist of stacks of Sub Modules (SMs). Simplistically, from a protection point of view, the converter can be in one of two states; unblocked, or blocked.

When the converter is unblocked, the control is capable of influencing the state variables, through the manipulation of the SMs. When the converter is blocked, the control is unable to influence the state variables. During the period the converter is blocked, the state variables are driven by the power system's forcing functions (ac and dc grid voltages etc).

Due to the converter's switching trajectory, the circuit cannot be described by a single equivalent circuit across the entire protection time. As such, the converter's fault response must be broken down into a sequence of stages. Between each stage within the sequence, the electrical circuit changes due to a controlled or uncontrolled switching of devices within the converter. The following sections describe key stages in the MMC's fault sequence. These stages can occur very rapidly, resulting in the converter's equivalent circuit changing many times before the circuit breaker is opened.

This analysis allows the fault currents to be described once the configuration of the converter is known. The analysis is kept general and includes the influence of the cable voltage until the last step of simplification. The resulting equations are therefore attempting to predict the fault currents from a $0 \mathrm{~km}$ fault.

\section{A. Stage A-Discharge}

The converter's first stage in the fault sequence is the discharge stage. This stage starts at the moment the fault is seen by the converter until the converter is blocked.

During this time the MMC's SMs will discharge through the dc side inductance, at a rate defined by the voltage that is presented across the dc side inductor.

It is possible that before the converter is blocked the SM sorting algorithm within the converter will change which SMs are inserted. This potentially exposes all SMs within the converter to some amount of discharge. Assuming that

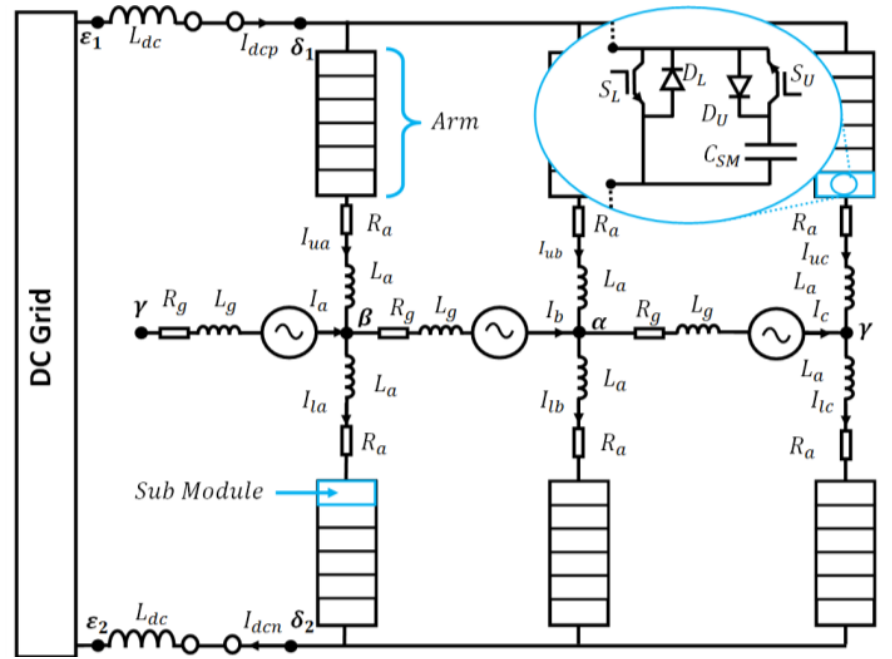

Fig. 4. HB Modular Multi-level Converter (MMC) and two de circuit breakers connected to a dc grid.

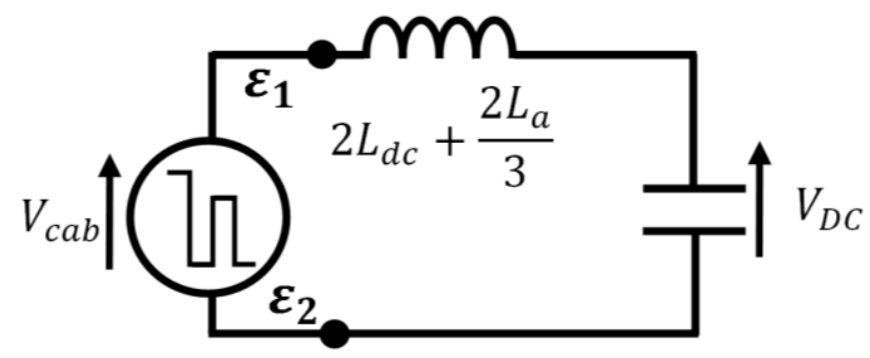

Fig. 5. Stage A equivalent circuit diagram.

significant discharge of the SMs is prohibited in order to maintain the ability to switch the IGBTs within each SM, and that the converter will attempt to maintain the dc link voltage during this discharge, Fig. 5 shows the Thevenin equivalent circuit and the fault current during this time can be estimated using:

$$
\begin{gathered}
I_{D C_{A}}(t)=\left(1+k_{T W}\right) \frac{V_{D C}}{L_{E q u}} t+I_{0 A} \\
L_{E q u}=2 L_{D C}+\frac{2}{3} L_{a}
\end{gathered}
$$

$V_{D C}$ is the dc link voltage at the moment the fault occurs. $k_{T W}$ is a constant to compensate for the increased voltage across the equivalent dc inductance caused by the cable voltage; this value is bounded between 0 and 1 , and it proportionally relates the cable voltage to the dc link voltage [15]. $L_{E q u}$ is the Thevenin equivalent circuit inductance, given by (2). The characteristic impedance of the cable is assumed to small relative to the dc side reactor impedance.

An important note here is that when the arm current is positive at the moment the converter is blocked, the inserted capacitors will continue to discharge until the arm current has reached zero. This can result in a slight delay between the converter block signal being sent and the beginning of the second stage.

\section{B. Stage B-Free Wheeling}

The second stage is the Free Wheeling stage. This stage starts after the converter is blocked and continues, as is 
explained in this section, until the moment a current zero crossing(s) occurs in a converter arm. The moment a zero crossing occurs in any of the converter's arms, the equivalent circuit changes and another set of equations must be developed.

Blocking a converter prevents the SM voltage from driving the fault current. It also causes the fault current to commutate out of the IGBTs in the SMs and start to flow in the diodes of the lower switches $\left(D_{L}\right.$ in Fig. 4). At this moment all six arms act as diode stacks, and each leg of the converter carries a third of the dc line current. The converter layout is now represented by Fig. 6.

As all six diodes are forward biased, this exposes all three phases of the ac grid to a reduction in load impedance. Thus the ac grid will be exposed to an increase in current. However this will not be a short circuit to the ac system as the arm inductors provide some impedance. The ac grid is not capable of contributing to the dc fault current level at this stage, and this is explained as follows.

Consider the voltage that would appear across $\delta_{1}$ and $\delta_{2}$ (Voltage nodes marked on Fig. 4 and Fig. 6) due to the influence of a single phase of the ac system. Providing the arm impedances match, the ac system voltages, and impedances are balanced, then each phase's contribution to the dc link voltage will have the same magnitude. This does not imply that the ac grid is subjected to a balanced set of currents. When the phase angle of these contributions is considered, these contributions will sum to zero. Thus, the ac grid cannot contribute to the dc fault while all six diodes are conducting. The ac grid voltages will influence the arm currents during this time.

However, the cable voltage is capable of forcing a change in the dc line current during this time. The cable voltage can become negative due to the inductive termination of the $\mathrm{dc}$ lines, which can increase the fault current. The fault current can be described using:

$$
\begin{gathered}
I_{D C_{B}}(t)=I_{02} e^{-\frac{R_{E q u}}{L_{E q u}}\left(t-t_{B}\right)}+I_{T W}\left(V_{c a b}, t\right) \\
R_{E q u}=\frac{2 R_{a}}{3}
\end{gathered}
$$

which is made up of two components; an exponentially decaying initial current $\left(I_{02}\right)$, and travelling wave component $I_{T W}$.

While the freewheeling condition is maintained on the dc side of the converter, the ac grid will be subjected to an increase in current, which will flow through the converter's arms, but not into the dc circuit breaker. The ac grid current will circulate in all possible paths within the converter. However, the majority of the phase currents will flow in the loops shown in Fig. 6. It can be seen that each phase-to-phase voltage increases the current in two arms, and decreases the current in two other arms. Each phase superimposes its own contribution to each arm current on top of the dc component. Fig. 7 shows a phasor diagram for the arm currents during this freewheeling stage. Each arm current is the sum of a dc component $\left(\frac{I_{D C}}{3}\right)$, and an ac component $\left(\tilde{I}_{x n}\right)$, as described by:

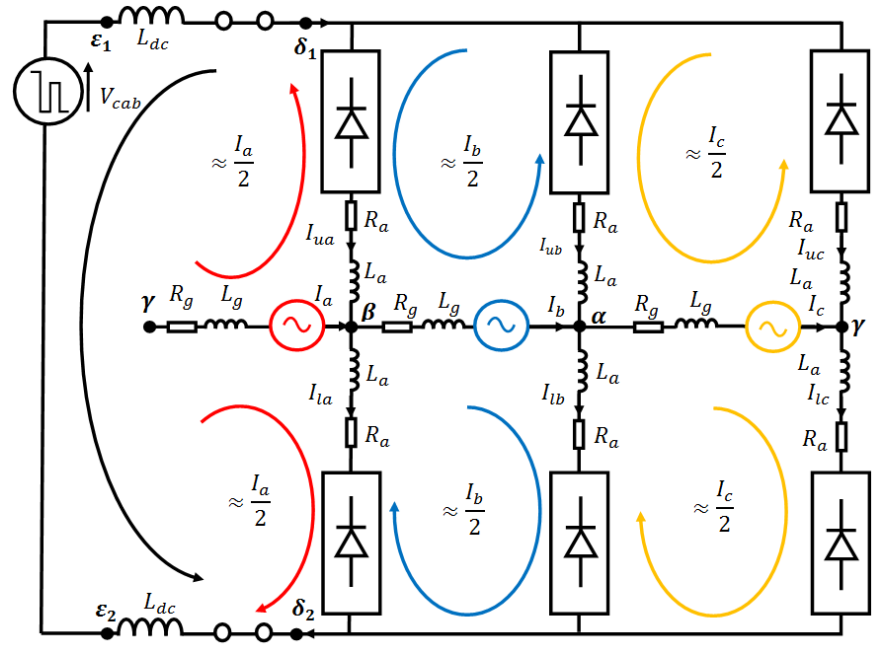

Fig. 6. Stage B equivalent circuit diagram.

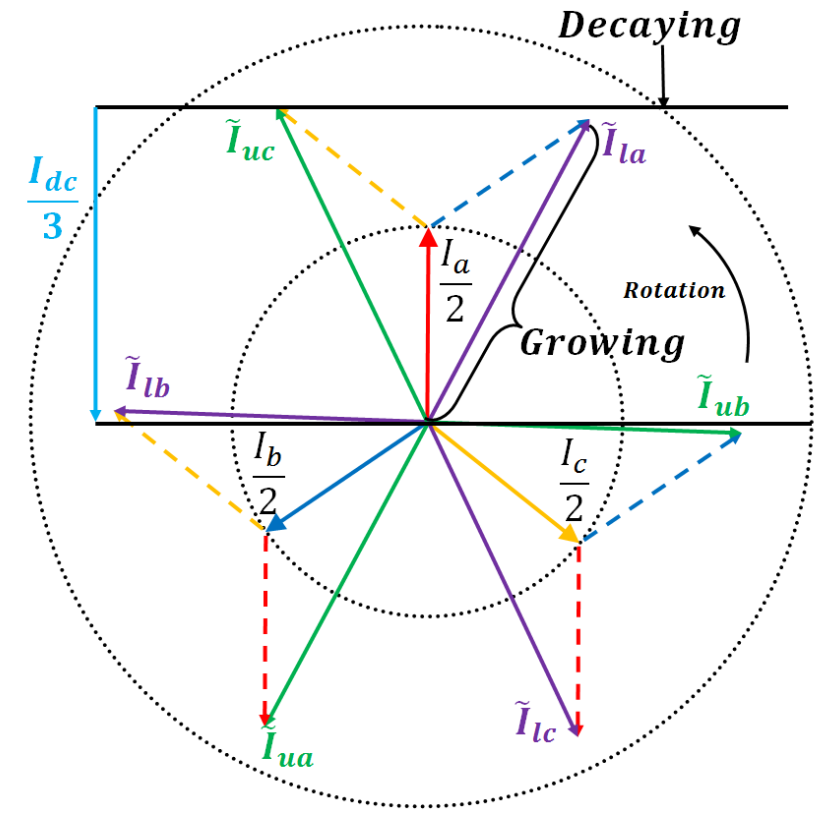

Fig. 7. Arm current phasor diagram, for Stage B. Dashed is negative of solid phase current of same color. Inner circle marks magnitude of half the phase current. Outer circle marks the magnitude of phase current.

$$
I_{x n}=\frac{I_{d c}}{3}+\tilde{I}_{x n}=\frac{I_{02}}{3} e^{-\frac{R_{E q u}}{L_{E q u}}\left(t-t_{B}\right)}+\tilde{I}_{x n}
$$

where $x$ denotes upper or lower arm positions and $n$ denotes the phase leg. The ac component of each arm current $\left(\tilde{I}_{x n}\right)$ is the difference of two separate phase current contributions.

During stage B the ac component of each arm current grows, while the dc component decays. This will eventually lead to a zero crossing in an arm, resulting in the converter moving to the next stage.

During the analysis of this stage, a generic problem was encountered that prohibited prediction of the time period the converter spends in Stage B, which is the main reason the time frames the converter spends in each stage could not be directly predicted. The issue is due to state variables being the sum of other state variables, making them dependent, one case being: 


$$
I_{D C}(t)=I_{u a}(t)+I_{u b}(t)+I_{u c}(t)
$$

This results in a singular matrix being formed during the state space anlaysis, which cannot be inverted. This prevents a prediction of the first zero crossing being made. If this problem can be overcome, then predictions for the time frame spent in each stage can be made, without the need for simulation. The other stages of the converter response do not encounter this issue. This is known as a cut-set problem.

\section{Stage C-Three Diode Rectifier}

Stage $\mathrm{C}$ starts at the moment three arms of the converter arms start conducting and ends at the next switching event. Fig. 8 shows the converter configuration for Stage $\mathrm{C}$, when three of the converter diodes are conducting. The three conducting diodes are spread across both upper and lower arms.

Fig. 8 can be reduced to the circuit in Fig. 9, where delta connection at the converter's terminals has been converted into an equivalent star connection. $L_{g}^{\prime}$ and $R_{g}^{\prime}$ are the ac grid impedances referred to the converter side of the transformer. This circuit can then be reduced into a Thevenin equivalent circuit shown in Fig. 10, when the circuit resistance is assumed to yield much lower impedance than the inductors. $V_{\text {cab }}$ is the cable's voltage at the point where it connects to the converter.

Using the Laplace transform is given by:

$$
\mathcal{L}\left\{\sin \left(\omega t+\theta_{n}\right)\right\}=\frac{\sin \left(\theta_{n}\right) s+\cos \left(\theta_{n}\right) \omega}{\omega^{2}+s^{2}}
$$

the dc fault current can be described by:

$$
I_{D C_{c}}(t)=\frac{\sqrt{3}\left|\widehat{V}_{L L}\right|}{L_{T} \omega_{a c}}\left[1-\cos \left(\omega_{a c} t+\theta_{C}\right)\right]+I_{0 C}
$$

Where

$$
L_{T}=2 L_{d c}+\frac{3}{2}\left(L_{a}+L_{g}^{\prime}\right)
$$

$\widehat{V}_{p n u}$ is the peak phase-to-neutral voltage that connects to the conducting upper arm during this period, $\widehat{V}_{L L}$ is the peak lineto-line voltage. The caret symbol $\left({ }^{\wedge}\right)$ is used to denote peak throughout this paper. For the opposing diode configuration (two upper arms, one lower arm conducting) this voltage would be the phase to neutral voltage connected to the conducting lower arm. The cable voltage has been ignored in (8) to provide a simplified result.

\section{Stage D-Four Diode Rectifier}

Another possible pseudo-rectifier operation is when four of the diode stacks in the converter are conducting. It is assumed that the four diodes are spread evenly across the upper and lower arms. The converter configuration is given in Fig. 8, with the additional upper arm diode marked in red. The equivalent circuit diagram is given in Fig. 9 with the additional arm path highlighted.

Assuming low circuit resistance, and considering the voltages and impedances to the right of nodes $\delta_{1}$ and $\delta_{2}$ then a reduced equivalent circuit can be found for this configuration,

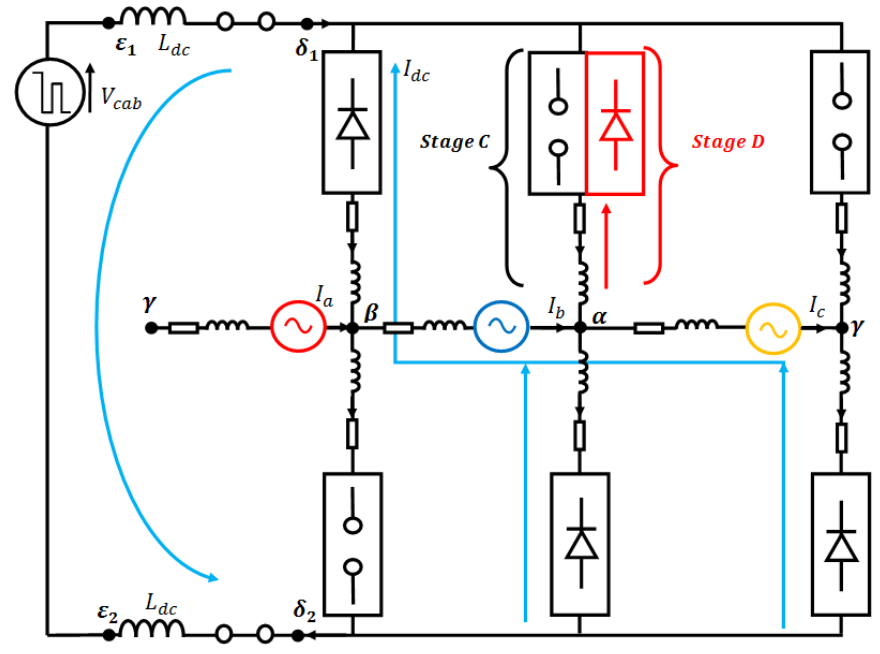

Fig. 8. Stage C \& D Converter configuration diagram. The additional diode for Stage D is highlighted in red. For Stage $\mathrm{C}$ this arm acts as an open circuit.

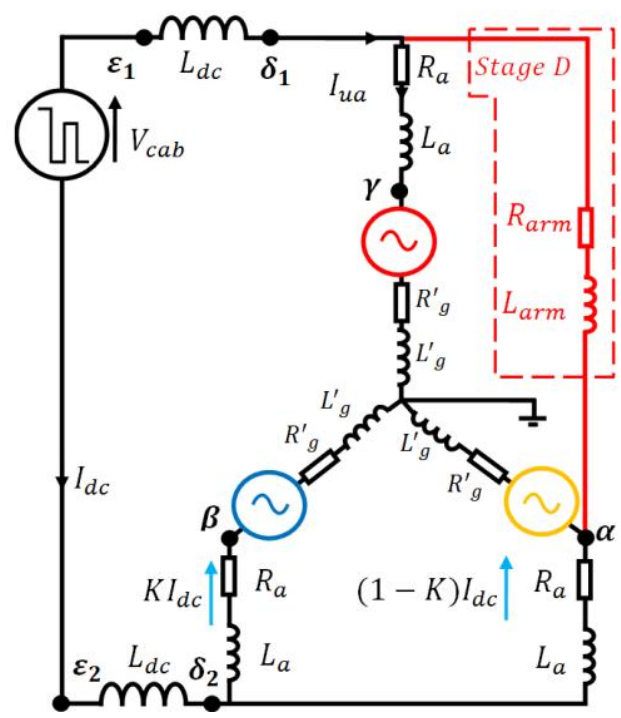

Fig. 9. Reduced equivalent circuit for stages C \& D.

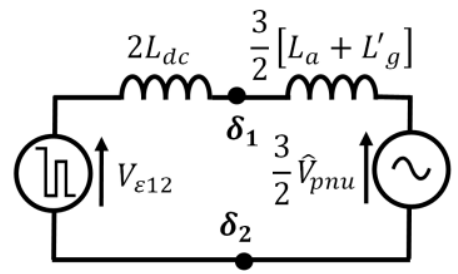

Fig. 10. Thevenin equivalent circuit for Stage C.

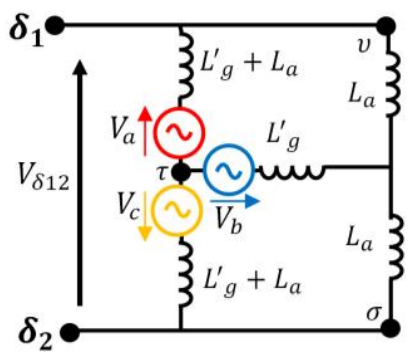

Fig. 11. Reduced equivalent circuit for Stage D.

shown in Fig. 11, indicating that only two of the phases are capable of providing a net contribution. Phase B in this case, cannot as the two contributions to voltage $V_{\delta 12}$ across the two 
impedances $L_{a}+L_{g}^{\prime}$ sum to zero, as they act in opposing directions and have the same magnitude. This will hold true providing that the converter arm and ac system impedances are balanced.

Fig. 11 can then be reduced to the Thevenin equivalent circuit, shown in Fig. 12, whose inductance is given by:

$$
L_{T h D}=\frac{2 L_{a}\left(L_{a}+L_{g}^{\prime}\right)\left(L_{a}+2 L_{g}^{\prime}\right)}{L_{g}^{\prime}\left(L_{a}+2 L_{g}^{\prime}\right)+L_{a}\left(2 L_{a}+3 L_{g}^{\prime}\right)}
$$

and Thevenin voltage is given by:

$$
V_{\delta 12}=\frac{\left|\widehat{V}_{L N}\right| \sqrt{3}}{2} \frac{L_{a}}{L_{a}+L_{g}^{\prime}}\left[\cos \left(\omega_{a c} t \pm \frac{\pi}{3}+\Theta_{D}\right)\right]
$$

This reduction has been performed using a star-delta transform on the nodes marked $(\tau, \sigma, v)$ in Fig. 11, then by subsuming impedance $L_{a}+L_{g}^{\prime}$ into one of the delta impedances, the circuit can be transformed back into a new star connection with reduced complexity.

Using the Laplace transform given in (7) and assuming the cable voltage influence is small, current during Stage D can be described by:

$$
\begin{aligned}
I_{D C_{D}}(t)=\frac{L_{a} \sqrt{3}\left|\hat{V}_{L N}\right|}{2\left(L_{T h D}+2 L_{d c}\right)\left(L_{a}+L_{g}\right)}[1 \\
\left.-\cos \left(\omega_{a c} t+\theta_{D}\right)\right]+I_{0 D}
\end{aligned}
$$

\section{E. Stage E-Fault Current Decay}

The final stage occurs at the moment the circuit breaker starts to generate the opposing voltage which starts to interrupt the fault current. The circuit breaker could open during any one of the stages described in the fault analysis sections of this paper. Hence is it important to understand the conditions that the circuit breaker may open under as the voltage $V_{\delta 12}$ will be different depending on the converter's configuration. Three possible values of voltage $V_{\delta 12}$ are given by:

$$
V_{\delta 12}=\left\{\begin{array}{c}
V_{D C} \\
\frac{3}{2} \hat{V}_{p n u} \\
\frac{\left|\widehat{V}_{L N}\right| \sqrt{3}}{2} \frac{L_{a}}{L_{a}+L_{g}^{\prime}}
\end{array}\right.
$$

However, for the case study results show in Section VII, the circuit breaker opens when the converter is in Stage C.

Based on the analysis presented in Section V.C, a reduced equivalent circuit can be derived for the moment at which the circuit breaker first attempts to interrupt the current, generating a voltage source $\left(V_{C B}\right)$ to oppose the flow of current, as shown in Fig. 13.

The current during this stage can be estimated by:

$$
I_{D C_{E}}(t) \simeq I_{0 E}-\frac{k_{v} V_{I N D}}{L_{E q u}}\left(t-t_{E}\right)
$$

Assuming that the ac system voltages, cable voltage, and varistor voltages are constant. $k_{v}$ is the allowed overvoltage ratio. $I_{0 E}$ is the initial current at the start of Stage E. $t_{E}$ is the time between fault inception and the circuit breaker attempting to interrupt the fault current. $\mathrm{V}_{\mathrm{IND}}$ is the voltage across $L_{D C}$.

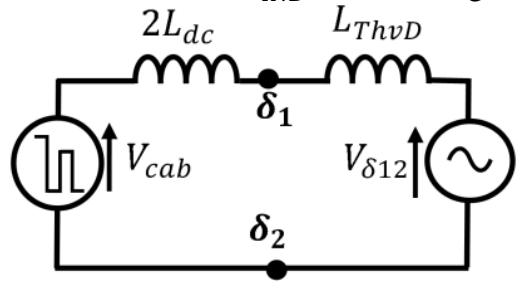

Fig. 12.Thevenin equivalent circuit for Stage D.

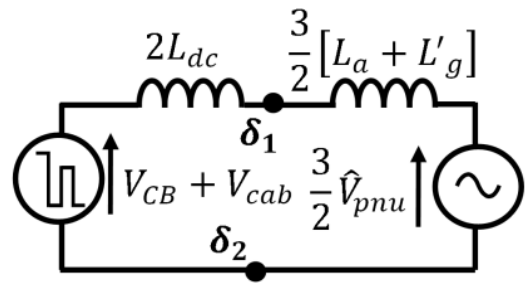

Fig. 13. Stage E: Reduced equivalent circuit when opening in stage C.

From this analysis it can be seen that when a circuit breaker opens in Stage C, in order for the varistor to force a negative current change in the fault current, the varistor voltage must be able to overcome 1.5 times the ac phase to neutral voltage plus any additional influence from travelling waves, based on:

$$
V_{I N D}=\frac{3}{2} V_{p n u}-V_{C B}-V_{c a b}
$$

However, what value of cable voltage is suitable for design purposes is not clear, as this voltage is likely to vary depending on the dc grid arrangement, as will be discussed in further detail in Section VII.C. If the cable voltage becomes negative, due to reflections in the dc grid, this may change the power flow recovery profile or damage the circuit breaker. This represents a lower limit for the peak voltages expected across the circuit breakers.

\section{CONVERTER CONTROLS}

As the converter is used in a new transmission environment, there will be a change to the converter's requirements. These requirements will need to be met, at least in part, by different converter controls. An overview diagram of the converter controls in this paper given in Fig. 14.

This section of the paper gives a brief discussion of response of the original controls used in the converter simulations and additions that have been introduced to improve the power flow recovery. The converter's power flow recovery, shown in Fig. 15, was gradually improved from the Original Response (OR) through the following steps. Details of the system modeling are given in Section VII.

\section{A. Original Response (OR)}

The converter's original power flow response to a dc protective action is shown in Fig. 15, along with the converter's blocking signal. When a de fault occurs resulting in a large de fault current relative to the maximum current limit of the converter's arms, the converter will be required to block. The only cases where this would not happen, is when the protection is fast enough or the dc side impedance is large enough, to prevent a significant arm current. 
The converter remains blocked until the circuit breaker

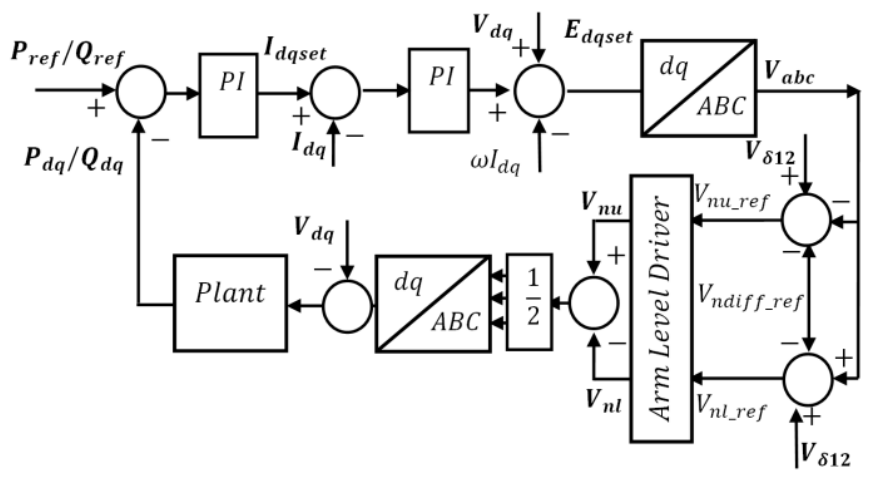

Fig. 14. Control system layout for power and current loops.

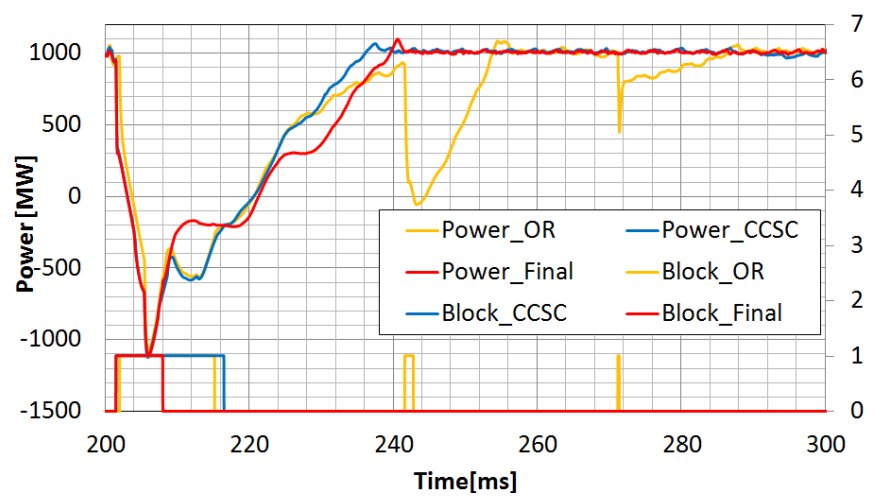

Fig. 15. PCC power flow recovery and blocking signals for a range of control strategies when subjected to a $0 \mathrm{~km}$ fault.

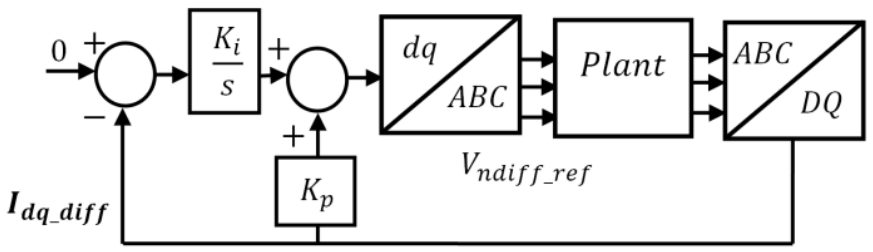

Fig. 16. DQ circulating current controller with two degrees of freedom.

recloses and the arm currents have decayed to a reasonable value to allow the converter to continue operating. It can be seen in the original response, additional blocking occurs after the protection has reclosed. This is causes unnecessary disturbance to the ac system.

\section{B. Circulating Current Suppressing Control}

In order to totally remove the unnecessary tripping of the converter, a Circulating Current Suppression Controller (CCSC) was added in the PSCAD simulations, the structure of which is shown in Fig. 16. This allows the converter to have control over the arm currents. The controller was designed based around [21, 24]. The original transfer function was based on [21] and the transfer function for the CCSC given in (16). $K_{i}$ is the controller integral term, $K_{p}$ is the proportional term. The CCSC's PI controller was modified to (17) using the structure outlined in Fig. 16. The modified controller response does not contain overshoots in arm current recovery response, shown in Fig. 17. The improvement in the power flow recovery can be seen in traces marked as "CCSC" in Fig. 15.

\section{Final Control}

In order to reduce the peak fault currents seen by the circuit

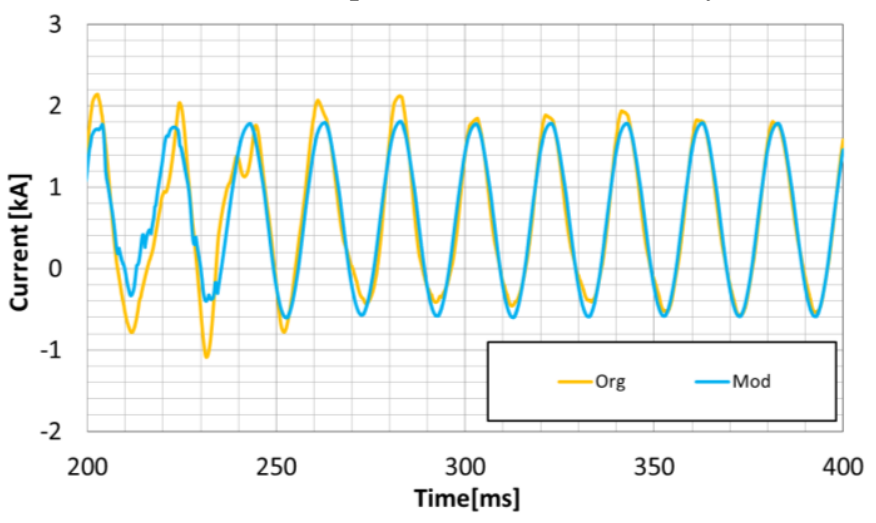

Fig. 17. Comparison of Original and Modified arm current controller performance during dc side pole-to-pole fault. Arm current shown is the upper arm of phase a.

$$
\begin{gathered}
H_{o r}(s)=\frac{\frac{K_{i}+K_{p} s}{L}}{s^{2}+\left(\frac{R+K_{p}}{L}\right) s+\frac{K_{i}}{L}} \\
H_{m d}(s)=\frac{\frac{K_{i}}{L}}{s^{2}+\left(\frac{R+K_{p}}{L}\right) s+\frac{K_{i}}{L}} \\
L=\frac{L_{a}}{2}+L_{a c} \\
R=\frac{R_{a}}{2}+R_{a c}
\end{gathered}
$$

breaker, and decrease the amount the SMs discharge, it was decided that upon the detection of a fault the converter should block. Providing fault detection occurs before the arm currents rise beyond their limits, this blocking scheme reduces the amount of sub module discharge. This reduced the time the converter was blocked for, as shown in Fig. 15.

In order to improve the converter's power flow recovery further the following additions were made to converter's control loops: Anti-integral windup and resettable controller integral terms.

Anti-integral wind up was added to mitigate the impacts of controller saturation that were observed in the simulations. Blocking decouples the system's manipulated variables and state variables. The manipulated variables are the converter arm voltages. The state variables are driven by the power system (ac grid or SM voltages etc). This means that while the converter is blocked the integral terms drift away from their desired values. The anti-integral windup and resettable integral terms were added to mitigate this problem. This reduces the amount of time the converter spent in the blocked condition, as can be seen in the traces marked as "Final" in Fig. 15.

\section{Converter Blocking and Unblocking Signals}

If the converter blocks during a dc side fault, then the criteria for blocking and unblocking is an important part of the protection system design. 
The criteria for unblocking a converter after a dc side fault when circuit breakers are used has yet to be established, as this has not been required in point-to-point systems, as fast $(<10$ ms) recovery is not required.

Unblocking quickly causes the submodules to discharge into the dc line, as the dc grid voltage will be lower than the normal dc voltage, post fault isolation.

Delaying unblocking, allows the ac grid to recharge the line. Thus, when the converter unblocks, the discharge current experienced by the submodules is lower, as the dc voltage is higher, reducing the current in the IGBTs. Finding the right conditions to unblock is an interesting and necessary area of future research and influences the recovery of the converter.

For this paper the converter blocks once any of the arm currents exceeds an internal maximum of $3.5 \mathrm{kA}$ or if the fault detection system confirms the presence of a fault, and will remain blocked until the unblock criteria are met. The converter will unblock when DC side current has reduced below $0.1 \mathrm{kA}$ and all the arm currents are below $2.5 \mathrm{kA}$. For the parameters used in these cases studies, the fault detection system is able to block the converter before the arm current levels are violated.

\section{CASE STUDIES}

The MMC converter was modeled using a Detailed Equivalent Model (DEM). The converter parameters are given in Table II. The converter arrangement is shown in Fig. 3. The power traces are measured on the ac grid side of the transformer at the PCC. The time period that the converter spends in each stage is determined through simulation. The terminal fault simulations provide verification that the above analysis is correct for the terminal fault case.

The faults are detected by measuring the cable voltage and generating a signal when this collapses below $80 \%$ of its nominal value. A $1 \mathrm{~ms}$ delay is then added to this signal to replicate the performance of a real fault detection system.

In each simulation the converter is subjected to a dc fault at $200 \mathrm{~ms}$ and the fault is detected 1 millisecond after fault inception. The circuit breaker imposes a counter voltage 5 millisecond after fault inception. Then the circuit breaker recloses once the dc fault current reaches zero. The converter unblocks once all arm currents are less than $2.5 \mathrm{kA}$ and the dc line current is less than $100 \mathrm{~A}$, at which point the converter attempts to reestablish power flow. It is assumed that the faulted section of the grid is isolated by other circuit breakers in the dc grid, through the open grid philosophy.

The first simulations were performed to verify the pole-topole fault analysis performed in Section V. The second set of results show the control prevents unnecessary blocking of the converter when it is subjected to a range of pole-to-pole fault conditions. In each simulation the converter is delivering or absorbing $1 \mathrm{GW}$ from the ac grid it is connected to and power is monitored at the Point of Common Coupling (PCC) in the ac network.

\section{A. Analysis Verification Study}

Fig. 18 and Fig. 19 shows a plot of the fault current from a
$0 \mathrm{~km}$ fault and a plot of the number of diodes conducting

Table II

Case Study Converter Parameters.

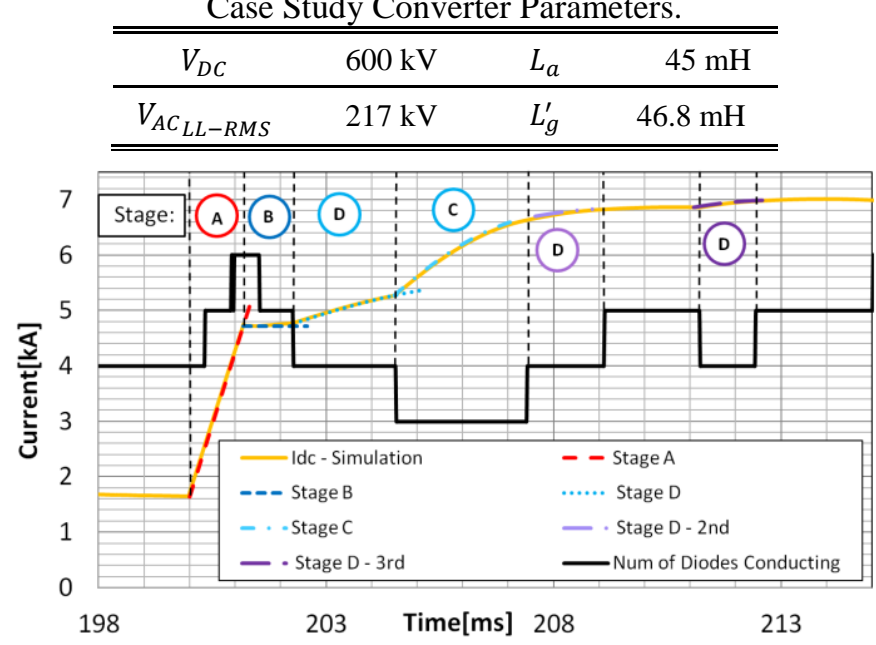

Fig. 18. Uninterrupted terminal fault $(0 \mathrm{~km})$ current for the converter working in rectifier mode. Calculations are compared to fault current at each switching event.

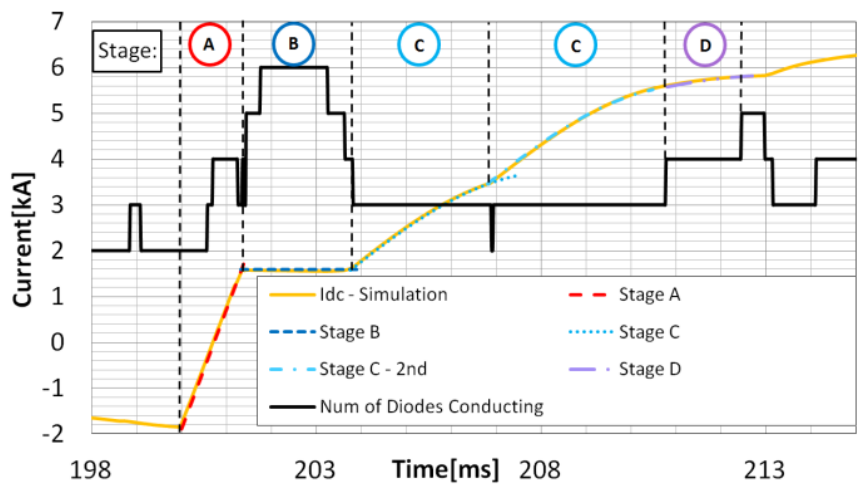

Fig. 19 Uninterrupted fault current from a terminal fault $(0 \mathrm{~km})$. at the inverter and a plot of the number of diodes conducting. Fault current is compared to equations developed for each stage.

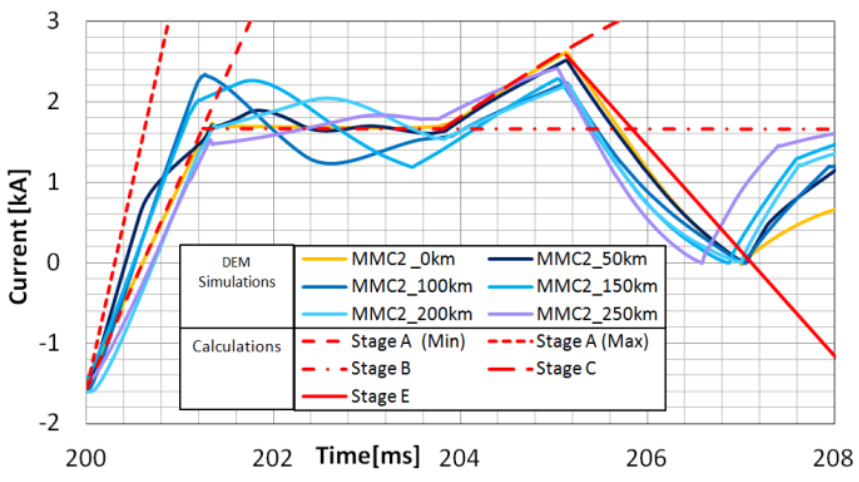

Fig. 20 Fault currents for rectifying operation compared to the analysis developed in Section IV.

within the converter, when the converter is acting as an inverter and rectifier respectively. The number of diodes indicates which stage the converter is in during its fault sequence. PSCAD simulation and analytical results are both shown. For Stage B, the equation has been compared to the simulation over the time period where it transitions between five and six diodes conducting, and vice versa. The equation is still relevant in this configuration as the converter does not 
significantly influence the fault current when five diodes are conducting. This may not hold true for all parameter ranges.

The results show a strong agreement between the simulation and the analysis (when the analysis is evaluated assuming the cable voltage is zero). The analysis for the case when five diodes are conducting has not been included in this paper. However, the amount the current changes during this stage is minimal for the parameters in these simulations.

Fig. 20 shows that the predictions provide a strong guide line for estimating the fault currents which occur at a distance from the converter. The traveling waves can increase the fault currents above those in a $0 \mathrm{~km}$ fault; due to the negative cable voltage increasing the rate-of-change of current. The maximum and minimum currents expected during stage A are shown. The maximum Stage A case is a theoretical limit, based on a complete reversal of the cable voltage $\left(\mathrm{V}_{\mathrm{cab}}=-\mathrm{V}_{\mathrm{DC}}\right)[15]$.

\section{B. Power Flow Recovery Study}

The associated power flow recovery profile for each of the fault current simulations is given in Fig. 21. The results show that the converter power flow is recovers within $40 \mathrm{~ms}$ of the fault inception, additional time is occasionally required for faults which are further away when compared to the $0 \mathrm{~km}$ fault, showing that the cable voltage influences the power flow recovery profile. There is also no additional blocking of the converter once the converter unblocks.

Fig. 22 shows that even though circuit breaker reduces the dc line current to zero, and forces a change in current in some arms, other arm currents remain significant. The arm currents must be returned to within normal operating magnitudes and orientation with respect to the other arms currents in order to regain the initial power flow condition.

As part of the recovery process, energy must also flow from the ac grid back into the dc system to recharge the cables. This current inrush causes problems and is difficult to control with the HB-MMC converter topology, and may result in converter tripping. This inrush current can be seen to be oscillatory in Fig. 22, and occurs due to energy flowing from the ac grid to recharge the dc line. The unblocking criteria affect the structure of this inrush current, as discussed in Section VI.D.

One major advantage of advanced MMC topologies (full bridge or Alternate arm converter) will be their ability to limit post fault inrush currents, or improve the recovery profile of the power at the PCC [7, 25], although this feature is not widely discussed. Other methods may attempt to use the dc switch gear to limit these inrush currents [19].

\section{Varistor Voltage Case Study}

To highlight the impact the cable voltage has on the recovery of the dc fault currents an additional case study has been performed. In this case study the circuit breaker knee voltage has been reduced to $220 \mathrm{kV}$, the lower limit defined by (15) being $225 \mathrm{kV}$ per breaker. The fault simulations were then re-run over the range of fault distances.

A plot of the cable voltages during protective actions has been given in Fig. 23 and the dc fault currents are plotted in Fig. 24. The circuit breaker imposes a voltage across itself to

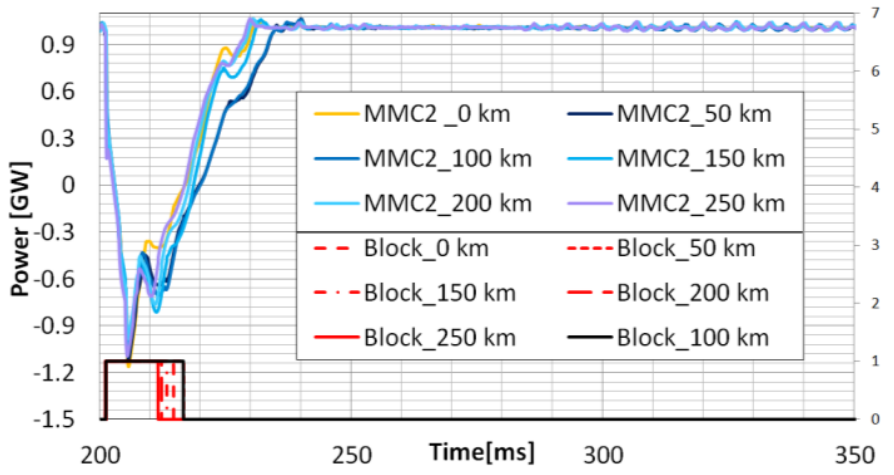

Fig. 21. PCC power flow recovery and blocking signals over a range of different faults.

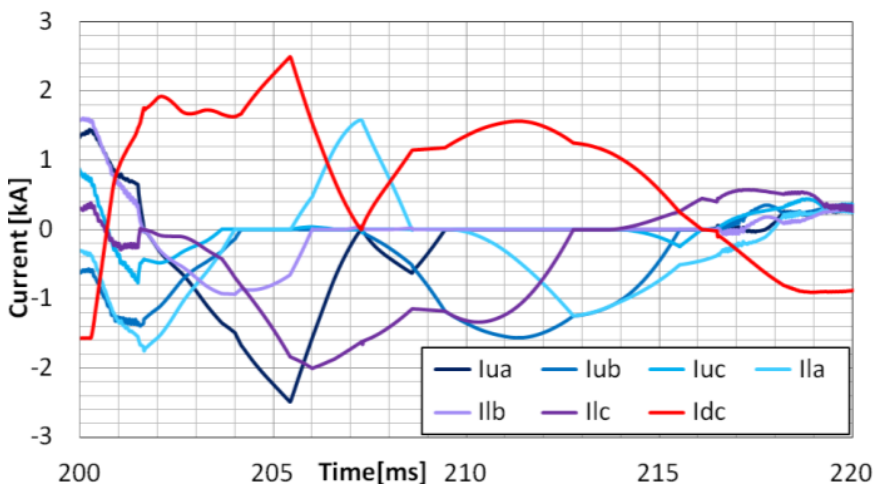

Fig. 22. Arm and dc line currents during protective action and fault recovery.

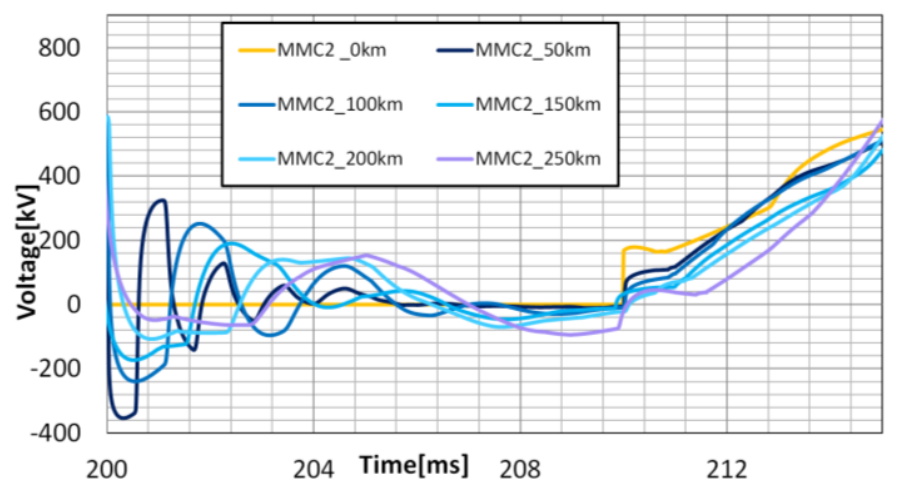

Fig. 23. Cable voltages during breaking transient at various distances.

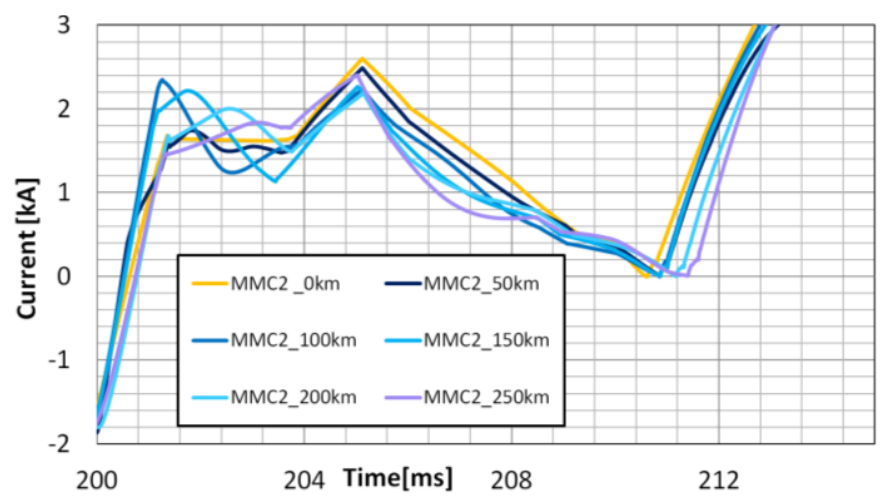

Fig. 24. DC Fault currents with reduced varistor knee voltage.

oppose the flow of current at $205 \mathrm{~ms}$. The cable voltage varies due to travelling waves that are still propagating through the dc grid, for faults that occur at a distance, with approximately a $300 \mathrm{kV}$ swing in cable voltage seen in the $250 \mathrm{~km}$ case. The 
traveling waves change the initial voltage at $205 \mathrm{~ms}$ which will change the recovery process. The profile the cable voltage takes will highly depend on the structure of the dc grid and any other transients which may impact the dc cable voltage during a protective action. In the worst case, a disturbance could cause the cable voltage to become negative, preventing the circuit breakers reducing the dc line current, resulting in a slower power recovery or even a failure of the protection.

The impact this has on the dc current is shown in Fig. 24, impacting the time current zeros occur and therefore the recovery profile at the $\mathrm{PCC}$, which is seen in the earlier results in Fig. 21 where the power flow recovery takes longer for faults at a distance.

\section{CONCLUSIONS}

The HB MMC fault response needs to be described by a sequence of fault responses, rather than a single fault response due to the controlled and uncontrolled switching of the converter's power electronics. This paper has provided generalized analysis to predict the dc fault current and how the fault current is distributed among the converter arms. For other converter topologies, the same process can be followed.

Once the time frames that the converter spends within each stage of its fault sequence have been established, an analysis of the dc fault current recovery process can be performed. This paper presents an analysis for dc fault current recovery in one of these stages, and provides an equation dictating the minimum arrestor knee voltage for the dc circuit breaker.

During the recovery stage the dc fault current is reduced to zero. However, this does not mean that the converter's arm currents have decayed to zero as well. The arm currents must recover to reasonable values before power flow can be reestablished.

The converter control system needs to be designed to encompass the additional requirements imposed by the dc fault recovery process. This paper has presented a first generation control method to remove unnecessary blocking of the converter; however improvements to power flow recovery need to be investigated further as this design may not be suitable under all scenarios.

Faults on the dc cables are likely to impact the ac system for a time period much longer than the time it takes to clear the fault. Based on the results shown in this paper, the disturbance exists for at least two cycles.

Traveling waves in the dc cables significantly influence the fault currents seen by the circuit breaker and can result in higher currents in many instances.

\section{REFERENCES}

D. V. Hertem, O. Gomis-Bellmunt, and J. Liang, "Drivers for the development of hvdc grids," in Hvdc grids:For offshore and supergrid of the future, ed: Wiley-IEEE Press, 2016, pp. 3-24.

[2] L. Chuanyue, H. Xiaobo, G. Jingli, and L. Jun, "The dc grid reliability and cost evaluation with zhoushan five-terminal hvdc case study," in Proc. Power Engineering Conference (UPEC), 2015 50th International Universities, 2015, pp. 1-6.

[3] H. Rao, "Architecture of nan'ao multi-terminal vsc-hvdc system and its multi-functional control," Power and Energy Systems, CSEE Journal of, vol. 1, pp. 9-18, 2015.
A. Hassanpoor, J. Häfner, and B. Jacobson, "Technical assessment of load commutation switch in hybrid hvdc breaker," Power Electronics, IEEE Transactions on, vol. 30, pp. 5393-5400, 2015.

J. P. Dupraz and D. L. Penache, "Development of a $120 \mathrm{kv}$ direct current circuit breaker," presented at Cigre Paris, 2014.

W. Zhou, X. Wei, S. Zhang, G. Tang, Z. He, J. Zheng, Y. Dan, and C. Gao, "Development and test of a 200kv full-bridge based hybrid hvdc breaker," in Proc. Power Electronics and Applications (EPE'15 ECCE-Europe), 2015 17th European Conference on, 2015, pp. 1-7.

M. M. C. Merlin, T. C. Green, P. D. Mitcheson, D. R. Trainer, R. Critchley, W. Crookes, and F. Hassan, "The alternate arm converter: A new hybrid multilevel converter with dc-fault blocking capability," Power Delivery, IEEE Transactions on, vol. 29, pp. 310-317, 2014.

R. Li, G. P. Adam, D. Holliday, J. E. Fletcher, and B. W. Williams, "Hybrid cascaded modular multilevel converter with dc fault ridethrough capability for the hvdc transmission system," IEEE Transactions on Power Delivery, vol. 30, pp. 1853-1862, 2015.

R. Zeng, L. Xu, L. Yao, and B. W. Williams, "Design and operation of a hybrid modular multilevel converter," IEEE Transactions on Power Electronics, vol. 30, pp. 1137-1146, 2015. G. P. Adam, K. H. Ahmed, S. J. Finney, K. Bell, and B. W. Williams, "New breed of network fault-tolerant voltage-sourceconverter hvdc transmission system," Power Systems, IEEE Transactions on, vol. 28, pp. 335-346, 2013.

G. Chaffey and T. C. Green, "Reduced dc circuit breaker requirement on mixed converter hvdc networks," in Proc. PowerTech, 2015 IEEE Eindhoven, 2015, pp. 1-6.

C. D. Barker, R. S. Whitehouse, A. G. Adamczyk, and M. Boden, "Designing fault tolerant hvdc networks with a limited need for hvdc circuit breaker operation," presented at Cigre, Paris, 2014.

W. Wang, M. Barnes, O. Marjanovic, and O. Cwikowski, "Impact of dc breaker systems on multi-terminal vsc-hvdc stability," Transactions on Power Delivery, 2015.

D. Döring, D. Ergin, K. Würflinger, J. Dorn, F. Schettler, and E. Spahic, "System integration aspects of dc circuit breakers," IET Power Electronics, vol. 9, pp. 219-227, 2016.

O. Cwikowski, B. Chang, M. Barnes, R. Shuttleworth, and A. Beddard, "Fault current testing envelopes for vsc hvdc circuit breakers," IET Generation, Transmission \& Distribution, vol. 10, pp. 1393-1400, 2016.

R. Li, L. Xu, D. Holliday, F. Page, S. J. Finney, and B. W. Williams, "Continuous operation of radial multiterminal hvdc systems under dc fault," IEEE Transactions on Power Delivery, vol. 31, pp. 351-361, 2016.

C. D. Barker and R. S. Whitehouse, "An alternative approach to hvdc grid protection," in Proc. AC and DC Power Transmission (ACDC 2012), 10th IET International Conference on, 2012, pp. 16.

W. Leterme, S. P. Azad, and D. V. Hertem, "A local backup protection algorithm for hvdc grids," IEEE Transactions on Power Delivery, vol. 31, pp. 1767-1775, 2016.

M. Callavik, A. Blomberg, J. Hafner, and B. Jacobson, "The hybrid hvdc breaker.," 2012.

ABB. 2013. 5sna 2000k450300 igbt datasheet. Available: http://new.abb.com/semiconductors/stakpak, (Accessed:July 2013.) A. Beddard, "Factors affecting the reliability of vsc-hvdc for the connection of offshore windfarms," Doctor of Philosophy, The University of Manchester, 2015.

W. Leterme, P. Tielens, S. D. Boeck, and D. V. Hertem, "Overview of grounding and configuration options for meshed hvdc grids," IEEE Transactions on Power Delivery, vol. 29, pp. 2467-2475, 2014.

A. Beddard and M. Barnes, "Hvdc cable modelling for vsc-hvdc systems," Washington DC, IEEE PES GM Conference, 2014.

Q. Tu, Z. Xu, and J. Zhang, "Circulating current suppressing controller in modular multilevel converter," in Proc. IECON 2010 - 36th Annual Conference on IEEE Industrial Electronics Society, 2010, pp. 3198-3202.

G. P. Adam and I. E. Davidson, "Robust and generic control of full-bridge modular multilevel converter high-voltage dc transmission systems," IEEE Transactions on Power Delivery, vol. 30, pp. 2468-2476, 2015. 